\title{
Blended synchronous learning environment: Student perspectives
}

\author{
Sheri Conklina ${ }^{\mathrm{a}}$, Beth Oyarzun ${ }^{\mathrm{b}}$, Daisyane Barreto ${ }^{\mathrm{c}}$ \\ ${ }^{a}$ University of North Carolina Wilmington,USA,conklins@uncw.edu \\ ${ }^{b}$ University of North Carolina Charlotte,USA, beth.oyarzun@uncc.edu \\ ${ }^{c}$ University of North Carolina Wilmington, USA, barretod@uncw.edu
}

\begin{abstract}
Distance education environments can take many forms, from asynchronous to blended synchronous environments. Blended synchronous learning environment (BSLE) can be defined as an innovative setting in which students can decide to attend classes either face-to-face or via a synchronous virtual connection. Many educators are unfamiliar teaching in BSLE because of lack of experience or exposure to this delivery method. Thus, it is important to understand the optimal organisational structures and the effective management of BSLE courses to facilitate student learning and interaction. Seeking to understand this teaching method, an exploratory mixed-method study was conducted to examine graduate students' perceptions of the BSLE. Quantitative and qualitative data was collected from a questionnaire and analysed. The findings revealed that students were satisfied with the BSLE, interactions, and the instructor. However, findings showed that the instructor divided attention between face-to-face and online synchronous students, which can cause cognitive overload and compromise the quality of instruction. Additionally, this study suggests that technical difficulties can affect students' satisfaction with BSLE courses. Implications for further research and limitations are discussed.
\end{abstract}

Keywords: interaction, blended synchronous learning environments (BSLEs), student satisfaction

\section{Introduction}

Online education is growing in the United States, especially in higher education settings. According to the Institute of Education Statistics (IES), higher education enrolment has increased. Distance education programme enrolment went from 2\% in 2000 to 16.3\% in 2012 (National Center for Education Statistics, 2014). There are approximately 17 million students enrolled in higher education institutions in the United States; this number is predicted to jump to more than 20 million by 2021. Online enrolment has increased from 1.2 million students in 2002 to 7.1 million students in 2012 (Allen \& Seaman, 2015). Online course offerings are also growing to accommodate a diverse student audience, such as deployed military or students who are at a geographical distance from higher education institutions. One of the emerging trends is how universities are redesigning their learning spaces to accommodate remote communication (New Media Consortium and Consortium for School Networking, 2017).

\section{BSLE environment}

BSLEs are defined as live environments with the instructor(s) present in a physical classroom and students having the option to attend class either face-to-face or virtually from a virtual classroom such as Cisco WebEx or Adobe Connect. This multimodal delivery of instruction allows flexibility and collaboration among face-to-face and online students. In other words, this type of environment combines two or more learning settings in one flexible environment (Hastie, Hung, Chen \& Kinshuk, 2010). Both face-to-face and online students have the ability to interact with the instructor(s), as well as their online and face-to-face peers. This ability to interact with students both online and face-toface enables the instructor(s) to create a unique learning community (Oyarzun \& Martin, 2013).

A previous study (Oyarzun \& Martin, 2013) has shown that students expressed appreciation for having the choice, which is determined by students' proximity to the university campus, on whether to attend class in a physical environment or virtually. The ability to collaborate and chat with all students, i.e. face-to-face or online, enrolled in the class is instrumental to creating a cohesive environment. Additionally, it is important that students have the ability to chat with their peers both publicly and privately (Oyarzun \& Martin, 2013). Face-to-face and virtual students should $\log$ 


\section{Blended synchronous learning environment: Student perspectives}

Conklinaa, Oyarzunb, Barretoc

into the virtual classroom or environment for face-to-face and online peer interactions to occur. BSLE classrooms should be equipped with proper technology to promote not only interaction but also a sense of presence. For example, a BSLE classroom should be fitted with two cameras: one for the instructor(s) and content, and another camera to capture the classroom. The secondary camera captures the 'real' physical space and allows online students to see their face-toface peers, which increases social presence and awareness in the learning environment (Oyarzun \& Martin, 2013). The BSLE environment must be designed to allow social presence and instructor interaction to be effective.

Along with the physical set-up of the classroom environment, another popular pedagogical approach used to address student and instructor interaction is transactional distance (Moore, 1993). Transactional distance refers to the cognitive distance between instructor and students within the online setting. There are three types of interactions in transactional distance theory: interactions with (1) content, (2) instructor, and (3) learners. Moore (1993) encouraged instructors to carefully plan how these interactions would occur when designing courses for online students. Grounded on Moore's interaction typology, a framework, also known as Community of Inquiry (CoI), has been developed, comprising three overlapping constructs: teaching presence, social presence, and cognitive presence (Garrison, Anderson, \& Archer, 2003). Recent research suggests that a fourth construct, namely, instructor presence or instructor social presence, should be added to this framework (Pollard, Minor, \& Swanson, 2014). Instructor presence includes developing patterns of interaction, providing feedback, moderating discussions effectively, and providing content expertise to discussions (Arbaugh \& Hwang, 2006).

\section{Interaction in the BSLE}

The BSLE is different from a face-to-face and an online synchronous environment since it combines both online and face-to-face environments to create a blended space. Nippart and Murphy (2007) found that teaching presence could be established using synchronous two-way audio and video as these tools can allow participants to see and hear one another in real time. Thus, the BSLE allows for face-to-face students and online students to participate in activities with the instructor and peers, independent of geographical location. Still, delays in the audio from the instructor(s) to the online students and vice versa can occur during classes (Oyarzun \& Martin, 2013). It is important for the instructor to be aware of communications and purposefully pause to ensure online students have an adequate chance to participate in dialogue with their face-to-face peers. It is also important for the instructor(s) to give equal attention to both the face-toface and online students. For instance, in a recent study, face-to-face students have indicated feeling neglected by their instructor because the instructor spent more time focussing on the online students instead of on face-to-face students (Szeto, 2015). Indeed, instructors teaching in the BSLE need to plan and attend to students in both face-to-face and online spaces to avoid negative feelings towards the instructional mode. Additionally, instructors need to develop organised lessons due to the complexity of interacting with both the online and the face-to-face students (Bower, Dalgarno, Kennedy, Lee, \& Kenney, 2015).

The complexity of teaching in the BSLE can be overwhelming. In fact, many instructors have felt that delivering instruction in the BSLE can increase cognitive overload due to the focus on two groups of students with varying needs as well as the need to distribute the instructor attention among the face-to-face students, online students, and the chat feature. For example, Szeto (2015) noted that instructor-to-student interactions overshadowed the student-to-student and student-to-content interactions. The author also indicated that additional active learning activities should be built into the learning experience to balance the three types of presence.

The social presence of online students can be different from that of face-to-face students. For instance, Szeto and Chang (2014) explored the types of interactions to create social presence and patterns that emerged in the BSLE. Students were assigned to either an online group or a face-to-face group. Findings suggested higher intra-group interactions (student-student) for the face-to-face group; however, the online group had higher inter-instructor interactions (student-instructor) than the face-to-face group. Overall, the face-to-face group was more apt to seek consultation from peers, whereas the online students preferred to consult with the instructor. It was also noted that student-student interactions did not happen outside their immediate vicinity (Szeto \& Chang, 2014). Grouping strategies, such as grouping online students with face-to-face students, could potentially "level the playing field" and create more interactions between the online and face-to-face students (Bower et al., 2015). Garnering student feedback as to why they seek input either from the instructor or from peers may assist in understanding why students prefer one method over the other and could assist in the design of effective interactions.

\section{Challenges in the BSLE}

Research has identified other challenges associated with the BSLE, such as technology (Szeto 2014; Szeto \& Cheng, 2014), promoting interaction between face-to-face and online students (Stewart, Harlow, \& DeBacco, 2011), and the ability of the instructor to give equal attention to both online and face-to-face students (Cunningham, 2014, Szeto, 2014; Szeto \& Cheng, 2014). Many educators are also not versed in teaching in the BSLE; therefore, it is imperative to understand the following: (a) what the BSLE is, (b) the best organisational structure for implementing lessons, and (c) effective management of the class to facilitate student learning and interaction. Organisation and design of effective 
interactions is essential to create a successful and cohesive class among face-to-face and online students as well as to lessen the instructor's cognitive and affective load during teaching (Bower et al., 2015; Teng, Chen, \& Leo, 2012). During the implementation of a lesson, instructors need to involve students and encourage contribution to keep students engaged with the course content and with each other, in addition to balancing the contributions of the students between the face-to-face and online groups of students (Bower et al., 2015; Szeto, 2015).

Technology is an important aspect of the BSLE, and professional development is essential for the instructor and students (Szeto, 2014). Both online and face-to-face students should become familiar with the technology used in BSLEs, as it is the platform for communication between the two groups of students and the instructor. Studies have shown that (a) students can be resentful when technology fails and the instructor takes class time to assist online students (Cunningham, 2014), and (b) audio lags can be detrimental to group cohesion (Bower et al., 2015; Szeto \& Cheng, 2014). Both face-to-face students and the instructor also need to be aware of the camera and microphones in the room to ensure that online students are able to view and hear the class discussion (Cunningham, 2014). With this in mind, it is important for the instructor to consider the type of technologies utilised as well as incorporate student training into the design of the course.

\section{Purpose of Study}

The BSLE is an innovative environment that is tailored to students who desire the convenience and choice of attending face-to-face classes locally or from a distance. Teaching online students while simultaneously working with students in a face-to-face environment can be an arduous task. The instructor needs to ensure that he/she interacts with both groups equally and promotes interaction between both groups to create a CoI. The purpose of this study was to determine how students perceive interactions within the BSLE. Student perceptions of interactions within the environment can assist in determining the best instructional strategies for this type of learning environment to create a cohesive group between the face-to-face and online students.

\section{Methods}

This exploratory design study examined student perceptions of the BSLE at the Southeastern University in the United States. This exploratory study used inductive methods to explore a phenomenon in order to develop generalisations. In this exploratory design study, quantitative and qualitative data was collected from a 34-item questionnaire, which was used to examine the perceptions of graduate students enrolled in BSLE courses. The questionnaire items included Likert items and semi-structured open-ended questions.

\section{Participants}

A purposeful sample (Patton, 2002) approach was implemented in this study. Only programmes that utilised the BSLE were included in this study. Participants were graduate students enrolled in the following programmes: Instructional Technology, Business Administration, Social Work, and Educational Leadership. Students received the questionnaire via email at the end of the semester during the summer and fall semesters of 2015.

During these two semesters, approximately 60 students received the questionnaire, with 30 students completing the entire questionnaire (50\%). The students' ages ranged from $<20$ years to 59 years, with a majority (49\%) being within the age range of 20-29 years. Twenty-five females and eight males participated in the study. Students had a range of experience in the BSLE: $29 \%$ were in their first semester, $23 \%$ were in their second semester, and $26 \%$ were in their third semester. Students were enrolled in a variety of programmes such as Educational Leadership (56\%), Business Administration (9\%), Instructional Technology (9\%), and Social Work (26\%). Students registered as either a distance education student or an on-campus student. Although some students lived at a distant geographical location and registered as a distance education student, they still had the option to attend face-to-face classes, if they preferred. Students who registered as on-campus students could also opt to attend online. From among the students who participated in the study, five preferred to attend online, 18 preferred face-to-face classes, and 12 preferred to alternate between attending online or face-to-face classes.

\section{Instruments}

A questionnaire was developed to ascertain students' perceptions of the BSLE, the instructor, and interactions between the face-to-face and online students. This tool was developed based on instruments developed by Sahin and Shelley (2008) as well as O'Malley and McCraw (1999). Changes to the questionnaire were minimal and comprised changes in the language to reflect the BSLE classroom instead of discussion boards. The questionnaire was divided into three sections: (a) environment, with 12 Likert questions; (b) instructor, including 10 Likert questions; and (c) interactions, with eight Likert questions. These items used a five-point response scale (1, strongly agree to 5. strongly disagree). After each section, participants received an open-ended question allowing elaboration to explain answers 


\section{Blended synchronous learning environment: Student perspectives \\ Conklinaa, Oyarzunb, Barretoc}

from the Likert items. A pilot study was conducted in the summer, and the questionnaire was validated with Cronbach's alpha of 0.873 .

\section{Results}

Given that students had the choice regarding how they would attend class if present or living locally, many of the students in this study stated that they prefer to alternate between attending online or face-to-face classes (Table 1). In addition, according to the percentage, most of the students preferred face-to-face classes (53\%), followed by preference for alternating between the two formats $(36.7 \%)$.

Table 1. Students' preferences for attending the blended synchronous classroom

\begin{tabular}{lcc}
\hline What is your preferred mode for attending classes in the BSLE? & Frequency & Percentage \\
\hline Online in WebEx & 3 & 10.0 \\
Face-to-face on-campus classes & 16 & 53.3 \\
I prefer to alternate between face-to-face and online classes & 11 & 36.7 \\
Total & 30 & 100.0
\end{tabular}

Students were satisfied with instructor interactions (mean $[\mathrm{M}]=4.32, \mathrm{SD}=5.42$ ); however, the environment and interaction were rated lower (Table 2).

Table 2. The overall mean values for instructor, environment, and interaction

\begin{tabular}{|c|c|c|c|c|c|}
\hline Factors & $\mathbf{N}$ & Range & Minir & Maxi & Mean \\
\hline Interaction mean & 30 & 1.75 & 2.83 & 4.58 & 3.6694 \\
\hline Instructor mean & 29 & 1.40 & 3.60 & 5.00 & 4.3241 \\
\hline Environment mean & ר29 & 2.13 & 2.88 & 5.00 & 3.8276 \\
\hline Valid N (list-wise) & 28 & & & & \\
\hline
\end{tabular}

Table 2 displays the mean value for each section of the Likert items.

Interactions overall ranked the lowest with $X=3.67$. Two statements within the 12 questions ranked low for students (Table 3): The introductions enabled me to form a sense of community had an $\mathrm{M}$ value $=3.30(\mathrm{SD}=1.03)$ and Discussions are more impersonal in this environment had an $\mathrm{M}$ value $=3.13$ ( $\mathrm{SD}=1.26$ ). In the open-ended responses, one student stated, "There is a lot of interaction with the students who are in the face-to-face class, but it is hard/impossible to form individual classmate relationships with online peers. Sometimes we do breakout sessions with online peers, which is productive, but it often is somewhat difficult technologically." Another student commented, "If there is a class and a student chooses to use WebEx to attend the class, I feel they are more of an observer than a participant in class compared to their in-person classmate(s)."

Table 3. Questionnaire statements with mean student responses

\begin{tabular}{lll}
\hline Statement & Mean SD \\
\hline BSLE is an excellent medium for social interaction. & 3.6 & 1.06 \\
I felt comfortable conversing with both online and face-to-face peers through this medium. & 3.77 & 0.961 \\
I felt comfortable introducing myself in this environment. & 4.03 & 0.756 \\
The introductions enabled me to form a sense of community & 3.3 & 1.146 \\
I felt comfortable participating in discussions. & 3.97 & 0.915 \\
The instructors created a feeling of a community. & 3.8 & 1.03 \\
The instructors facilitated discussions. & 4.1 & 0.99
\end{tabular}


Discussions in the BSLE were impersonal.

Discussions are more impersonal in this environment.

I felt comfortable interacting with other participants.

I felt my viewpoint was acknowledged by other participants.

Students were overall satisfied with the instructor $(X=4.32)$. Students rated the constructs relating to the instructor being a fair, caring humble person with fairly high grades $(X>4.40)$. Where the instructor received the lowest mean related to the constructs creating unity $(X=4.03)$ and drawing the class together $(X=4.14)$. A couple of students stated that the instructor would sometimes forget to acknowledge the online students.

For distance education only students, it can sometimes be hard to comment or start in a conversation because an instructor might be asking questions solely and strategically to those in the room. I have had some professors specifically ask if anyone on WebEx had comments which really helped. Others rely solely on inclass participants and move so fast that it is difficult to get an opinion or question in. This problem is magnified when the instructor mutes WebEx students to prevent extraneous noise yet doesn't keep up to check if we have "raised our hand" (through a button) or wrote a comment. Just acknowledging that there are students both physically in and physically out of class makes a big difference.

Another student stated that online students do not feel they have the same opportunity to form a relationship with their instructors as their face-to-face counterparts. One student stated, “... However, I feel that less face to face time with the professor means less opportunity to build a helpful relationship....", while another student stated, "Also, I don't feel the same opportunity to build a strong working relationship with my professor in the BSLE mode."

Overall, the BSLE environment was rated high $(\mathrm{X}=3.82)$. Students agreed that this type of environment was flexible and met their needs $(X=4.10)$; yet, given the chance to take classes in the BSLE as a result of their experiences, students rated this much lower $(\mathrm{X}=3.37)$. One student noted:

I agree that this is a more convenient mode, especially for those with a long commute to class. However, I feel that less face-to-face time with the professor means less opportunity to build a helpful relationship. Also, due to the delay when WebExing, it is more difficult to engage, and to have a conversation when you do. Given the choice between going to the classroom with fellow students and WebExing in, even if the professor will be at the Wilmington campus, I always choose to go to the classroom because at least I will have face to face support from my fellow classmates when I do.

Another student made similar comments yet commented on the technology.

I think the BSLE provides a great opportunity for students who are not able to be in the physical classroom to still attend the lecture and participate in discussion, but there have been instances of technological difficulties that have inhibited online peers' interaction. One time the screen locked (with the tech admin's username) and we couldn't see the WebEx participants anymore. My professor for that class said we wouldn't worry about it since we could all still hear everyone, but I thought that was a bit unfair for the WebEx students (that it distanced them even more from the classroom). However, tech services showed up and unlocked the screen, most likely after one of the students messaged them.

\section{Discussion}

Themes such as technology, instructor cognitive overload, and equal attention arose from this study. Students were satisfied with the BSLE, interactions, and the instructor. First, the instructor can affect student satisfaction based on his/her interaction with both the online and the face-to-face students. Technology can also influence student satisfaction due to audio lags and the instructor's knowledge with basic troubleshooting skills. Based on the comments from the students, the instructor and the technology can greatly affect satisfaction with the BSLE. Regarding students' responses to instructor creating a sense of community and unifying the class, the low mean scores presented in this study might have been a result of cognitive overload of the instructor attempting to give equal attention to two groups of students in two environments (Bowers et al., 2015; Szeto \& Cheng, 2014; Szeto, 2015). Some studies (Rasmussen, 2003; Szeto, 
2015) found an unequal distribution of attention from the instructor to either the online or the face-to-face group, corroborating the results of this study. Additionally, Szeto (2015) found that the instructor overcompensated his attention towards online students, which led face-to-face students to perceive the instructor as dedicating more time on additional explanations specifically to online students. In contrast, Rasmussen (2003) found the instructor dedicating his attention towards the face-to-face students. The use of active learning strategies (e.g. whole class discussion, small group collaboration, or case studies) may engage and increase social presence among the students (Bower et al., 2015). Finally, recent research studies (Szeto \& Cheng, 2014; Bower et al., 2015) on this topic suggest appointing a student to monitor the text chat to ensure that all students can contribute to the discussion while at the same time reducing the cognitive overload on the instructor.

Although it was not collected, technology was a common theme that emerged in the open-ended questions. Technology barriers have been a common theme for many studies within the BSLE (Bower et al., 2015; Cunningham, 2014; Szeto \& Cheng, 2014). The ability of both the students and the instructor to navigate and troubleshoot the technology being used to connect the students from a distance is essential to ensuring student satisfaction and success within the BSLE. Cunningham (2014) has noted that failure with technology can result in student resentment and audio lags can be detrimental to creating group cohesion (Bower et al., 2015; Szeto \& Cheng, 2014). Students in this study mentioned the difficulty of working with their online peers due to low connectivity or the technical difficulty faced while participating in group work with their online peers. Bower et al. (2015) suggest that instructors participate in professional development programmes to ensure that they can properly use technology and assist students who may have technical difficulties. The authors also suggest that instructors log into the virtual room 10 minutes early to allow students time to troubleshoot any difficulties. Finally, it is suggested that all students, including face-to-face students, $\log$ into the virtual environment (Bower et al., 2015; Szeto, 2015). Therefore, students have the ability to interact with one another and assist each other with questions that may arise.

There needs to be a balance among the environment, instructor, and interactions to create a positive student experience (Figure 1).

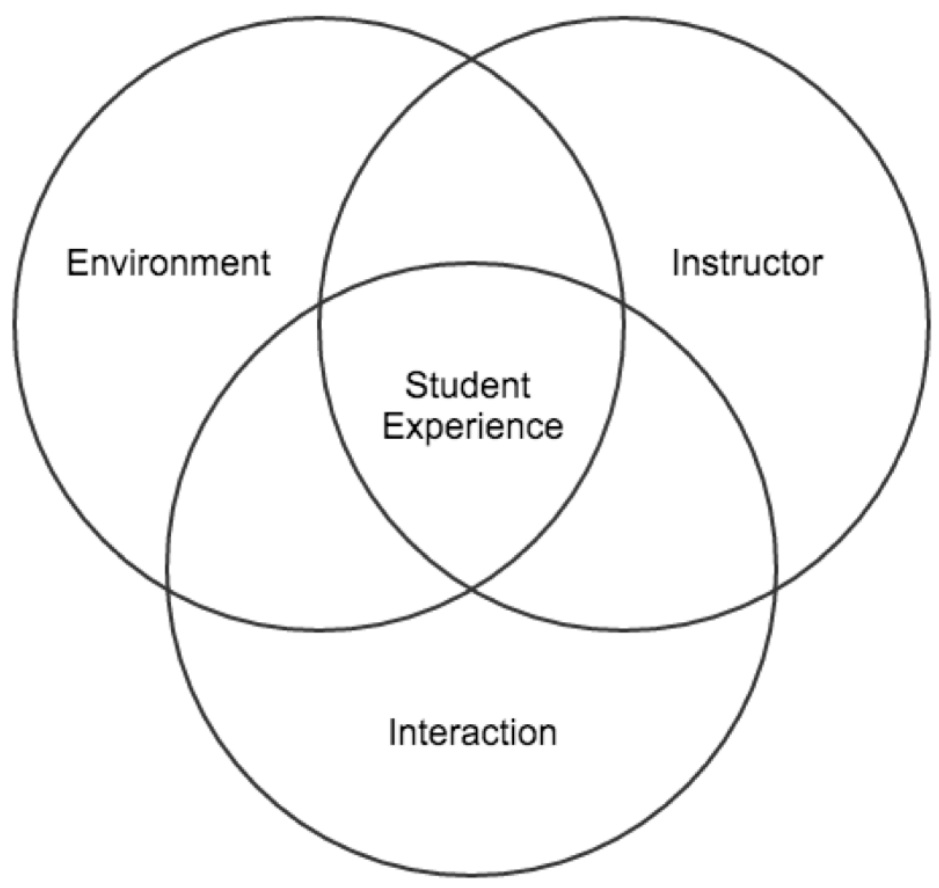

Fig. 1. Triangulation of environment, instructor, and interaction to create positive student experience.

The instructor needs to create active learning activities and test the technology in the course environment prior to class implementation. During this time, the instructor should determine how students should answer whole class questions. For example, students could be directed to type all instructor questions into the text chat in order to "level the playing field," which would allow both the face-to-face students and online students to answer the question simultaneously. Due to audio lags, typically, the online students have difficulty answering the question before the faceto-face students and can feel neglected (Bowers et al., 2015; Cunningham, 2014; Oyarzun \& Martin, 2013; Szeto, 2015). Using a variety of strategies, the instructor can increase interactions between the face-to-face and the online students and create a unified class. 


\section{Blended synchronous learning environment: Student perspectives}

Conklinaa, Oyarzunb, Barretoc

\section{Limitations and conclusions}

A limitation of this study was the sample size. The sample was limited to the faculty teaching in the BSLE during the summer and fall semesters. Many programmes that use the BSLE during the traditional semester deliver classes asynchronously during summer sessions. It is also unknown whether the faculty teaching in the blended synchronous programmes have received training or attended professional development courses on teaching within this type of environment. Faculty have the option to seek resources and professional development through instructional designers whose focus is distance education. Therefore, the instructors may not have the skills or expertise to conduct a class and create a community between the face-to-face and online students. Although there is a technical person available to assist blended synchronous classes, the technical person's assistance is limited as he or she monitors multiple classes at a time. Faculty also may or may not possess the technical skills to give immediate assistance to students when they have technical difficulties. Bower et al. (2015) recruited seasoned instructors who had taught in the BSLE and employed sound pedagogy and, therefore, this case study only provided information from those instructors who were extremely experienced.

Future research should include faculty interviews to ascertain technology skills and knowledge with BSLE pedagogy. In addition, a Blended Synchronous Learning Design Framework (Bower et al., 2015) has been developed, offering pedagogical, technological, and logistical recommendations for the BSLE; yet, the strategies within the aforementioned framework need to be validated and refined through future research. Further research should be conducted to determine student perceptions of social presence and the effects of social presence on their perceived learning and satisfaction (Richardson \& Swan, 2003).

\section{References}

Allen, I. E., \& Seaman, J. (2015). Grade level: Tracking online education in the United States. Babson Park, MA: Babson Survey Research Group and Quahog Research Group. Retrieved from http://www.onlinelearningsurvey.com/reports/gradelevel.pdf

Arbaugh, J. B. \& Hwang, A. (2006). Does "teaching presence" exist in online MBA courses? The Internet and Higher Education, 9(1), 9-21.

Bower, M., Dalgarno, B., Kennedy, G. E., Lee, M. J., \& Kenney, J. (2015). Design and implementation factors in blended synchronous learning environments: Outcomes from a cross-case analysis. Computers \& Education, 86, 117.

Cunningham, U. (2014). Teaching the disembodied: Othering and activity systems in a blended synchronous learning situation. The International Review of Research in Open and Distributed Learning, 15(6).

Garrison, D. R., Anderson, T., \& Archer, W. (2003). A theory of critical inquiry in online distance education. Handbook of distance education, 1, 113-127.

Hastie, M., Hung, I. C., Chen, N. S., \& Kinshuk. (2010). A blended synchronous learning model for educational international collaboration. Innovations in Education and Teaching International, 47(1), 9e24.

Moore, M. G. (1993). 2 Theory of transactional distance. Theoretical principles of distance education, 22.

National Center for Education Statistics (2014). STEM in Postsecondary Education (US Department of Education, Washington).

New Media Consortium., \& Consortium for School Networking. (2017). Horizon report. Austin, TX: The New Media Corsortium.

Oyarzun, B., \& Martin, F. (2013). A Case Study on Multi-Modal Course Delivery and Social Learning Opportunities. Bulletin of the IEEE Technical Committee on Learning Technology, 15(1), 25.

Pollard, H., Minor, M., \& Swanson, A. (2014). Instructor Social Presence within the Community of Inquiry Framework and Its Impact on Classroom Community and the Learning Environment. Online Journal of Distance Learning Administration, 17(2), n2.

Richardson, J. \& Swan, K. (2003). Examining social presence in online courses in relation to students' perceived learning and satisfaction. Journal of Asynchronous Learning Networks, 7(1), 68-88.

Rasmussen, R. C. (2003). The quantity and quality of human interaction in a synchronous blended learning environment. (Doctoral dissertation, Brigham Young University) Available from ProQuest Dissertations \& theses. (UMI No. 305345928)

Szeto, E. (2015). Community of inquiry as an instructional approach: What effects of teaching, social and cognitive presences are there in blended synchronous learning and teaching? Computers \& Education, 81, 191-201.

Szeto, E., \& Cheng, A. Y. (2014). Towards a framework of interactions in a blended synchronous learning environment: what effects are there on students' social presence experience? Interactive Learning Environments, 2 , $1-17$.

Teng, D. C. E., Chen, N. S., \& Leo, T. (2012). Exploring students' learning experience in an international online research seminar in the Synchronous Cyber Classroom. Computers \& Education, 58(3), 918-930. 